Please do not remove this page

RMIT

UNIVERSITY

\title{
Alkali ratio control for lead-free piezoelectric thin films utilizing elemental diffusivities in RF plasma
}

Nili Ahmadabadi, Hussein; Kandjani, Ahmad; Du Plessis, Johan; Bansal, Vipul; Kalantar Zadeh, Kourosh; Sriram, Sharath; Bhaskaran, Madhu

https://researchrepository.rmit.edu.au/esploro/outputs/9921861944401341/filesAndLinks?institution=61RMIT_INST\&index=null

Nili Ahmadabadi, H., Kandjani, A., Du Plessis, J., Bansal, V., Kalantar Zadeh, K., Sriram, S., \& Bhaskaran, M. (2013). Alkali ratio control for lead-free piezoelectric thin films utilizing elemental diffusivities in RF plasma. CrystEngComm, 15(36), 7222-7229. https://doi.org/10.1039/C3CE40508G

Document Version: Accepted Manuscript

Published Version: https://doi.org/10.1039/C3CE40508G

Repository homepage: https://researchrepository.rmit.edu.au

(c) The Royal Society of Chemistry 2013

Downloaded On 2023/04/26 10:45:38 +1000

Please do not remove this page 
Thank you for downloading this document from the RMIT Research Repository.

The RMIT Research Repository is an open access database showcasing the research outputs of RMIT University researchers.

RMIT Research Repository: http://researchbank.rmit.edu.au/

\section{Citation:}

Nili Ahmadabadi, H, Kandjani, A, Du Plessis, J, Bansal, V, Kalantar Zadeh, K, Sriram, S and Bhaskaran, M 2013, 'Alkali ratio control for lead-free piezoelectric thin films utilizing elemental diffusivities in RF plasma', CrystEngComm, vol. 15, pp. 7222-7229.

See this record in the RMIT Research Repository at:

http://researchbank.rmit.edu.au/view/rmit:22101

Version: Accepted Manuscript

Copyright Statement: (C) The Royal Society of Chemistry 2013

Link to Published Version:

http://dx.doi.org/10.1039/C3CE40508G 


\title{
Alkali ratio control for lead-free piezoelectric thin films utilizing elemental diffusivities in RF plasma
}

\author{
Hussein Nili, ${ }^{a}$ Ahmad Esmaielzadeh Kandjani, ${ }^{b}$ Johan Du Plessis,,${ }^{c}$ Vipul Bansal, ${ }^{b}$ \\ Kourosh Kalantar-zadeh, ${ }^{a}$ Sharath Sriram ${ }^{* a}$ and Madhu Bhaskaran ${ }^{* a}$ \\ ${ }_{5}$ Received (in $\left.X X X, X X X\right)$ Xth $X X X X X X X X X$ 2013, Accepted Xth XXXXXXXXX 2013 \\ DOI: $10.1039 /$ c0ce00000x
}

High performance piezoelectric thin films are generally lead-based, and find applications in sensing, actuation, and transduction in realms of biology, nanometrology, acoustics, and energy harvesting. Potassium sodium niobate $(\mathrm{KNN})$ is considered to be the most promising lead-free alternative, but is 10 hindered by the inability to control and attain perfect stoichiometry materials in thin film form while using practical large area deposition techniques. In this work, we identify the contribution of elemental diffusivities in radio frequency (RF) plasma in determining alkali loss in KNN thin films. We have also examined the effect of substrate temperature during the RF-magnetron sputtering deposition on the crystal structure of the substrate and KNN thin films, as well as the effect of post-annealing treatments. These 15 results indicate the need for well-designed source materials and the potential to use deposition partial pressures to alter dopant concentrations.

\section{Introduction}

Alkali-based potassium sodium niobate, $\mathrm{K}_{\mathrm{x}} \mathrm{Na}_{1-\mathrm{x}} \mathrm{NbO}_{3}(\mathrm{KNN})$, material system is one of the most promising lead-free substitutes 20 for the dominant ferroelectric lead zirconate titanate (PZT) system owing to its good piezoelectric properties, high Curie temperature, and modifiability by various dopants. ${ }^{1-4}$

$\mathrm{KNN}$-based thin films have been investigated extensively during the past ten years for applications ranging from optical ${ }_{25}$ waveguides $^{5,6}$ and FRAMs $^{7}$ to piezoelectric-based devices for energy harvesting applications. ${ }^{8-10} \mathrm{KNN}$-based thin films have been processed by a variety of techniques encompassing chemical deposition such as sol-gel ${ }^{11,12}$ and chemical solution deposition (CSD), ${ }^{13}, 14$ and physical deposition such as pulsed laser 30 deposition (PLD) $)^{3,15,16}$ and RF magnetron sputtering. 5, 7-10, 17-22 Among these, RF magnetron sputtering is promising due to its capability for large area depositions with lower growth temperatures that makes it viable for integration with fabrication processes. Major challenges in RF magnetron sputtering of KNN35 based thin films are non-stoichiometry due to volatility of alkali metals, ${ }^{18,23}$ formation of secondary phases, ${ }^{24}$ and high leakage current density. ${ }^{17,18}$

The loss of alkali metals during KNN thin film synthesis was noted in early attempts of PLD and RF magnetron sputtering. ${ }^{17,23 \text {, }}$

${ }_{40}{ }^{25}$ Further studies on the effects of different sputtering parameters on the composition, crystal structure, and growth rate of $\mathrm{KNN}$ thin films revealed that while crystalline phases and growth rate are largely dependent on sputtering pressure and growth temperature, alkali loss cannot be controlled by varying

${ }^{45}$ sputtering parameters. ${ }^{17,}{ }^{18,24}$ It was suggested then that the alkali volatility can be addressed by excess amount of $\mathrm{K}$ and $\mathrm{Na}$ species (usually in the ratio of $1.5: 1.5: 1$ for $\mathrm{K}: \mathrm{Na}: \mathrm{Nb}$ ) in sputtering targets. ${ }^{23}$ Most recently, Kim et al. ${ }^{22}$ have studied the effect of post-annealing treatment on the crystal structure and electrical 50 properties of $\mathrm{KNN}$ thin films grown on $\mathrm{Pt} / \mathrm{Ti} / \mathrm{SiO}_{2} / \mathrm{Si}$ substrates at a substrate temperature of $300{ }^{\circ} \mathrm{C}$ utilizing a stoichiometric target, in different annealing atmospheres. To our knowledge, until now, no comprehensive study has been carried out on the alkali loss and the compositional homogeneity of KNN thin films as a 55 function of oxygen partial pressure during the sputtering process. Such a study offers the potential to control elemental diffusivity during deposition to tailor alkali content and composition ratios. This creates the opportunity to attain different alkali ratios from a single target and also create tailored deficiencies in films for ionic 60 conduction for memristive applications.

This investigation aimed to study the correlation between varying oxygen partial pressure and post-annealing treatment on alkali loss, crystal structure, and surface morphology of KNN thin films as well as to design methods to control their ${ }_{65}$ composition and crystal structures using these parameters.

\section{Experimental details \\ KNN thin films deposition}

KNN thin films were deposited by RF magnetron sputtering on platinized silicon substrates with a $200 \mathrm{~nm}$ thick platinum layer 70 and a $20 \mathrm{~nm}$ thick titanium dioxide adhesion layer. A $100 \mathrm{~mm}$ diameter KNN target with the composition $\left(\mathrm{K}_{0.3} \mathrm{Na}_{0.7}\right) \mathrm{NbO}_{3}$ was used for all depositions. The composition of the target was verified using energy dispersive X-ray analysis (EDX) in a scanning electron microscope (SEM). To determine the role of 75 elemental diffusivities on the resulting alkali ratio, the role of 
oxygen partial pressure during deposition and the effect of postannealing in vacuum and gaseous atmosphere were investigated. The oxygen partial pressure in argon for the process gas during

Table 1 Sputtering and post-annealing conditions for KNN thin films

Substrate

Target

Process Gas

Base pressure

Sputtering Pressure

Substrate Temperature

RF Power

Sputtering Duration

Post-Annealing Treatment

(at $700{ }^{\circ} \mathrm{C}$ )

sputtering was varied from 0 to $40 \%$ in steps of $10 \%$ for each sputtering run. KNN thin films were subsequently post-annealed at $700{ }^{\circ} \mathrm{C}$ for 1 and $3 \mathrm{~h}$ in vacuum and in oxygen atmosphere to study the effects of post-annealing on their composition, surface

10 chemistry, and crystal structure. Table 1 summarizes sputtering and post-annealing conditions.

\section{X-ray diffraction}

The crystallography of the thin films was studied by X-ray 15 diffraction (XRD) using a Bruker D4 Endeavour diffractometer with a copper $K \alpha$ source. The patterns were collected with a stage rotation of $15 \mathrm{rpm}$ in the $2 \theta$ range between $20^{\circ}$ and $60^{\circ}$ in $0.02^{\circ}$ steps, with a collection time of $4 \mathrm{~s}$ at each step, in the BraggBrentano geometry to account for all possible crystal orientations 20 in the thin films.

\section{X-ray photoelectron spectroscopy}

X-ray photoelectron spectroscopy (XPS) surface and depth profile analyses were carried out using a Thermo Scientific KAlpha instrument. The surface composition analysis was ${ }_{25}$ performed in the central area of the samples with a $5 \mathrm{~mm} \times 1 \mathrm{~mm}$ spot size. An aluminum $K \alpha$ radiation source with energy of $1485 \mathrm{eV}$ was used, with the carbon peaks on the sample surface used as reference for calibration. The composition of the film was determined utilizing the area under the curves, fitted and 30 corrected with sensitivity factors using the Avantage data system. Depth profiling was performed by successive, repeated argon-ion etch and spectrometry processes. This was performed in five consecutive etching steps for $30 \mathrm{~s}$ each with low ion beam intensity.

\section{${ }_{35}$ Results and discussion}

Figure 1 shows the X-ray diffractograms for as-deposited KNN thin films under different oxygen partial pressures. Peaks have been indexed using powder diffraction files for orthorhombic platinum silicide (PtSi - ICDD Card No. 07-0251) ${ }^{26}$ and KNN 40 monoclinic (ICDD Card No. 74-2025) ${ }^{27}$ and tetragonal (ICDD Card No. 77-0037) ${ }^{28}$ structures. At the high temperature range of $\mathrm{KNN}$ thin films deposition, the $\mathrm{TiO}_{2}$ adhesion layer forms islands ${ }^{29,} 30$ providing the contact between the substrate and the platinum layers and allowing the diffusion of the platinum layer 45 into the silicon substrate ${ }^{29}$. The formation of $\mathrm{TiO}_{2}$ islands and the contact between platinum and silicon layers during high temperature oxide sputtering deposition on $\mathrm{Pt} / \mathrm{TiO}_{2} / \mathrm{Si}$ substrates have been previously verified through TEM analysis. ${ }^{31}$ Due to the high deposition temperature, the platinum bottom electrode has 50 been morphed into a polycrystalline platinum silicide layer with a strong (200) orientation. Strong (200) orientation of the platinum silicide layer has resulted in the formation of (002) oriented KNN structure (peak at $2 \theta$ of $46.1^{\circ}$ )..$^{32}$ Also, the KNN (101) peak at around $32.5^{\circ}$ is observed. The differences in the relative intensity 55 of the peak at around $32.5^{\circ}$ between as-grown thin films deposited at different oxygen partial pressures is evidence of the existence of $\mathrm{KNN}$

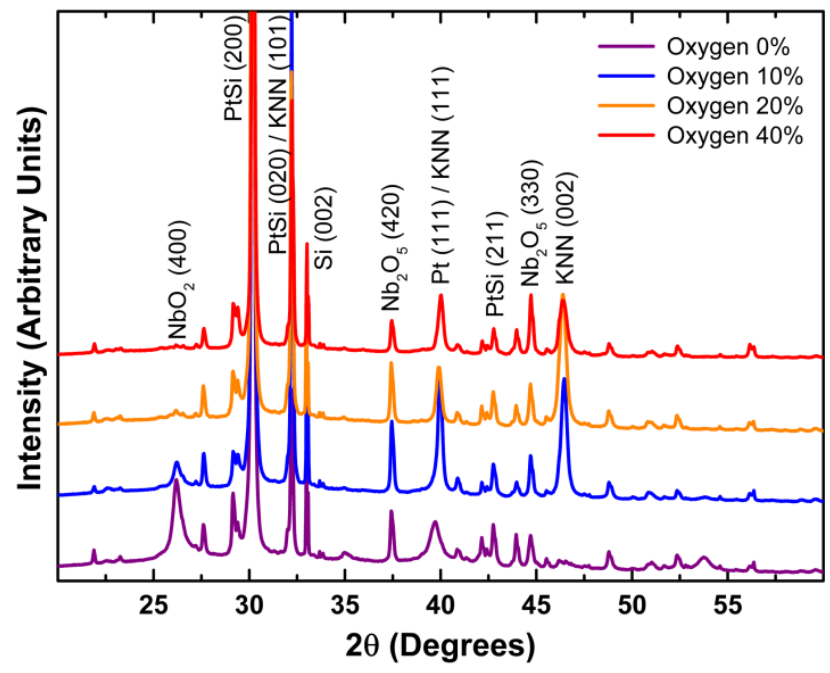

Fig. 1 X-ray diffractograms for as-deposited KNN thin films. Depositions 60 were performed at a substrate temperature of $700{ }^{\circ} \mathrm{C}$, with varying oxygen partial pressure.

(101) orientation in the films, which becomes more evident with results comparing the as-grown and post-annealed samples (discussed later).

${ }_{65}$ The appearance of secondary niobium oxide peaks in XRD can be primarily attributed to excess niobium compared to alkali metals in the films, resulting from the alkali loss during the RF magnetron sputtering with a stoichiometric target. To confirm niobium species indexed in the X-ray diffractograms and study 70 the effect of oxygen partial pressure and post-annealing treatments on the composition of the thin films, a thorough XPS analysis was conducted on the samples.

XPS elemental and depth profile analysis were carried out through the thickness of thin films to characterize elemental 75 ratios variation of sodium, potassium, niobium, and oxygen as a function of oxygen partial pressure and post-annealing treatments, and to determine the compositional homogeneity of the KNN thin films. The elemental ratios for different species are uniform within tolerance levels throughout the thickness of all 80 thin films, excluding the data acquired from the exposed surface of the films as it is subject to ambient contamination. Table 2 shows $\mathrm{K} /(\mathrm{K}+\mathrm{Na})$ ratio for $\mathrm{KNN}$ thin films grown under different oxygen partial pressure conditions and subjected to various postdeposition treatments, highlighting the impact of process gas and 85 post-annealing treatment on the alkali loss and ratio. A lack of oxygen in the sputtering atmosphere results in a dramatic loss of alkali species due to collisions with the argon ions in the RF 
plasma and thermal evaporation at the substrate end at high temperature. As a lighter element, sodium is more prone to the scattering mechanisms than potassium. ${ }^{33-35}$ Thus, KNN phase was not observed in the XRD pattern of KNN films deposited in a 5 pure argon atmosphere. The introduction of oxygen minimizes sodium loss, with the elemental ratios ranging from $31.7-41.3 \%$ (compared to the $30.0 \%$ for the target). Upon introduction of oxygen into the sputtering atmosphere, negative oxygen ions formed at the target surface get accelerated into the plasma 10 towards the substrate. The highly-energetic oxygen ions enhance the scattering of the ablated perovskite species of the oxide target ${ }^{36,37}$ which in turn leads to a decrease in the kinetic energy of the perovskite species. Since the sputtering species reach the substrate with a lower kinetic energy and surface mobility this 15 leads to the formation of preferentially ordered grains with smaller size. Further, oxygen pressure helps the oxidization of the sputtered species into higher oxidization states leading to the formation of $\mathrm{Nb}^{5+}$ species for the perovskite crystal structure. Post-annealing treatments in most cases do not show a significant 20 change in the as-grown alkali ratio; however, slight increases observed in most cases indicate further sodium loss.

The ratio of alkali to niobium concentration $[(\mathrm{K}+\mathrm{Na}) / \mathrm{Nb}]$, which is expected to be 1 (or $100 \%$ ), was also analyzed (see Table 3). The elevated loss of alkali metals in the sputtering 25 process is observed in all films leading to alkali-to-niobium ratios of 0.1-0.5 in the KNN thin films. This result supports reports ${ }^{23}$

Table $2 \mathrm{~K} /(\mathrm{K}+\mathrm{Na})$ ratio for $\mathrm{KNN}$ thin films grown under different oxygen partial pressure and subjected to various post-annealing treatments at $700{ }^{\circ} \mathrm{C}$. The $\mathrm{K} /(\mathrm{K}+\mathrm{Na})$ ratio of the sputtering target used is $30 \%$

\begin{tabular}{|c|c|c|c|c|c|}
\hline \multirow{2}{*}{$\begin{array}{c}\text { Oxygen Partial } \\
\text { Pressure (\%) }\end{array}$} & \multicolumn{5}{|c|}{ K/(K+Na) Ratio (\%) } \\
\hline & As-Grown & $1 \mathrm{~h}$ Vacuum & 3 h Vacuum & 1 h Oxygen & 3 h Oxygen \\
\hline 0 & 89 & 78 & 73 & 83 & 78 \\
\hline 10 & 32 & 39 & 17 & 42 & 43 \\
\hline 20 & 41 & 44 & 44 & 42 & 44 \\
\hline 40 & 41 & 40 & 50 & 43 & 42 \\
\hline
\end{tabular}

30

Table $3(\mathrm{~K}+\mathrm{Na}) / \mathrm{Nb}$ ratio for $\mathrm{KNN}$ thin films grown under different oxygen partial pressure and subjected to various post-annealing treatments at $700{ }^{\circ} \mathrm{C}$. $\mathrm{The}(\mathrm{K}+\mathrm{Na}) / \mathrm{Nb}$ ratio of the sputtering target used is $100 \%$

\begin{tabular}{ccccc}
\hline Oxygen Partial & \multicolumn{3}{c}{ (K+Na)/Nb Ratio (\%) } \\
\cline { 2 - 5 } Pressure (\%) & As-Grown & 1 h Vacuum & 3 h Vacuum & 1 h Oxygen \\
\hline 0 & 10 & 9 & 14 & 15 \\
10 & 45 & 27 & 56 & 50 \\
20 & 37 & 33 & 39 & 52 \\
40 & 28 & 25 & 33 & 43 \\
\end{tabular}

that a potential mechanism to compensate for alkali loss is to 35 have excess alkali concentration in KNN RF magnetron sputtering targets.

In order to understand the underlying mechanism and chemical-crystallographic phase changes resulting from such alkali loss, detailed analysis of the XPS spectra for sodium, 40 potassium, niobium and oxygen species in the KNN30 thin films was carried out. Figure 2 presents XPS spectra for these elements in the as-grown sample deposited under $20 \%$ oxygen partial pressure (chosen based on its preferential orientation, Fig. 1) after background correcting the as-obtained XPS spectra using Shirley ${ }_{45}$ algorithm, ${ }^{38}$ aligning the elemental binding energies to adventitious carbon (C1s) binding energy of $285 \mathrm{eV}$ and resolving chemically distinct species using a non-linear least square fitting procedure. ${ }^{39}$ Both potassium and sodium spectra were found to consist of a single component spectrum that can be ${ }_{50}$ correlated to KNN structure. Notably, as expected, K2p spectrum showed the spin orbital pair corresponding to $2 \mathrm{p}_{3 / 2}$ and $2 \mathrm{p}_{1 / 2}$. XPS spectrum for $\mathrm{Nb3d}$ shows three different spin orbital pairs, corresponding to three different niobium species: (i) $\mathrm{NbO}_{\delta}$ where $1<\delta<2$ at $204.3 \mathrm{eV}$; (ii) $\mathrm{NbO}_{2}$ at $205.8 \mathrm{eV}$; and (iii) $\mathrm{Nb}_{2} \mathrm{O}_{5}$ phase ${ }_{55}$ present in $\mathrm{KNN}$ (henceforth called $\mathrm{Nb}-\mathrm{KNN}$ ) at $207.7 \mathrm{eV} .^{40,41}$ Moreover, O1s spectrum could be de-convoluted into two components with binding energies at $530.7 \mathrm{eV}$ and $532.5 \mathrm{eV},{ }^{42}$ which correspond to $\mathrm{O}^{2-}$ ions in the structure of different niobium oxides, and the adventitious $\mathrm{C}-\mathrm{O}$ bonds adsorbed on to the ${ }_{60}$ sample surface, respectively.

Further, the effect of different post-annealing treatments on the composition of the thin films was examined by de-convoluting the Nb3d core level XPS spectra in corresponding spin orbital pairs. In as-grown samples and those post-annealed in vacuum for ${ }_{65} 1 \mathrm{~h}, \mathrm{NbO}_{\delta}, \mathrm{NbO}_{2}$, and $\mathrm{Nb}-\mathrm{KNN}$ related peaks were all present. However, in the thin films annealed for $1 \mathrm{~h}$ in oxygen, the $\mathrm{NbO}_{\delta}$ peak completely vanished and the peak related to $\mathrm{KNN}$ became significantly more prominent than that of $\mathrm{NbO}_{2}$ (based on the integrated peak area). This indicates that the annealing in an 70 oxygen environment for a sufficient amount of time increases the tendency of $\mathrm{Nb}$ to oxidize towards higher oxidation states, desirable for attaining the $\mathrm{Nb}_{2} \mathrm{O}_{5}$ state required for $\mathrm{KNN}$. Figure 3 shows the evolution of $\mathrm{Nb} 3 \mathrm{~d}$ peak for the film grown under $20 \%$ oxygen partial pressure as a result of post-annealing 75 treatments.

XPS spectra of Nb3d through the thickness of films were also used to determine the uniformity of the oxidation levels at different thickness levels of the sample. The films deposited under $10 \%, 20 \%$, and $40 \%$ oxygen partial pressures were studied. ${ }_{80}$ Figure 4 shows the relative concentration of the three different $\mathrm{Nb}$ species at four different depths within the film (based on four consecutive etch cycles).

The concentration of the $\mathrm{Nb}-\mathrm{KNN}$ species (as opposed to $\mathrm{Nb}$ 
species in oxides) decreases through the depth of films postannealed in vacuum irrespective of the oxygen partial pressure during the sputter deposition process. This phenomenon can be attributed to the lack of oxygen during annealing preventing $\mathrm{Nb}$ 5 from attaining a more stable higher oxidation state, as desirable for $\mathrm{KNN}$. Also, the amount of $\mathrm{NbO}_{2}$ is relatively uniform (about $20 \%$ ) at the different etch levels. This indicates that limited
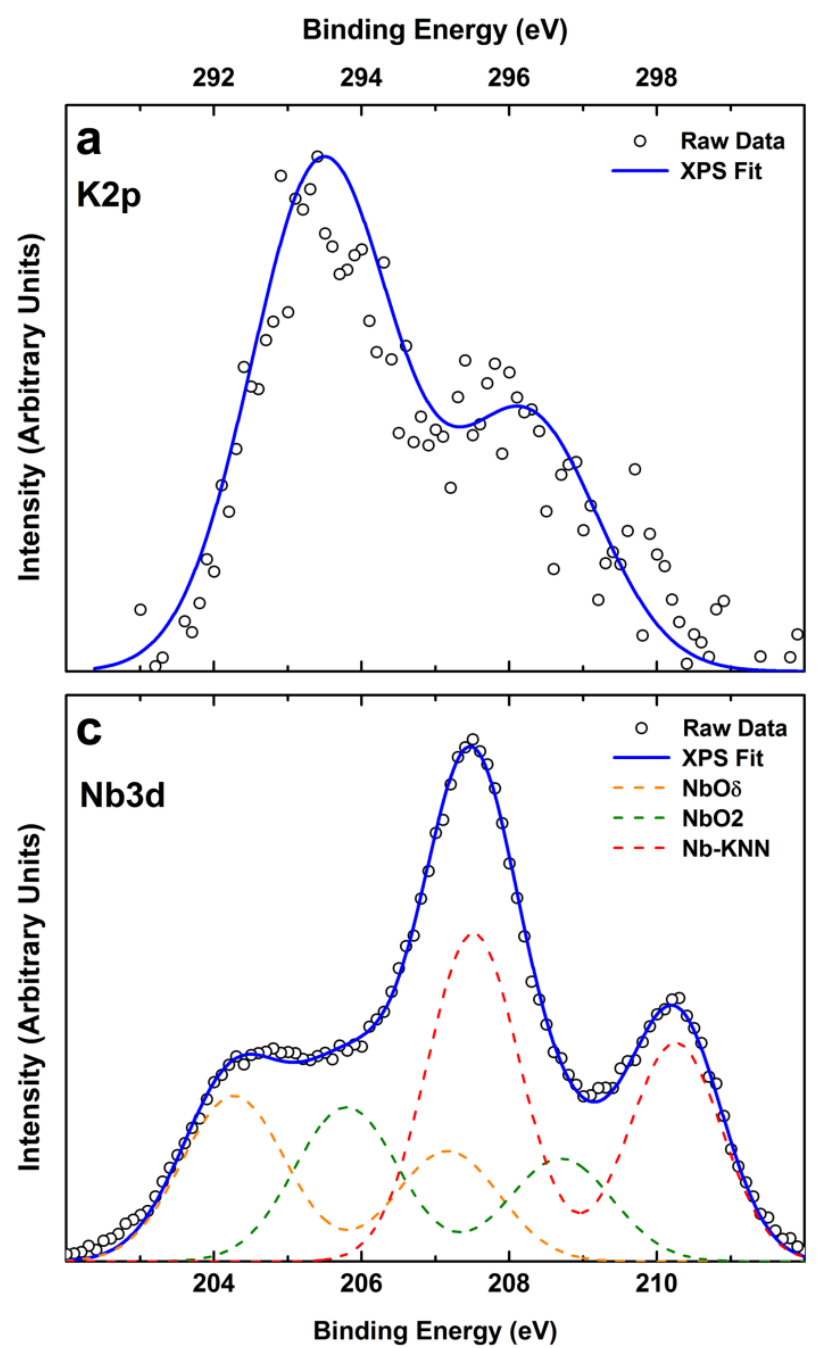

oxygen was available at greater depths in the film, resulting in the dominance of the sub-stoichiometric $\mathrm{NbO}_{\delta}$ species. On the other 10 hand, films post-annealed for $1 \mathrm{~h}$ in oxygen exhibit considerably higher $\mathrm{Nb}^{5+}$ species almost uniformly throughout the thickness. This indicates that post-annealing in oxygen atmosphere enables oxygen diffusion through the film thickness, promoting $\mathrm{Nb}^{5+}$ oxidation states $(\mathrm{Nb}-\mathrm{KNN})$ desirable for $\mathrm{KNN}$ thin films.
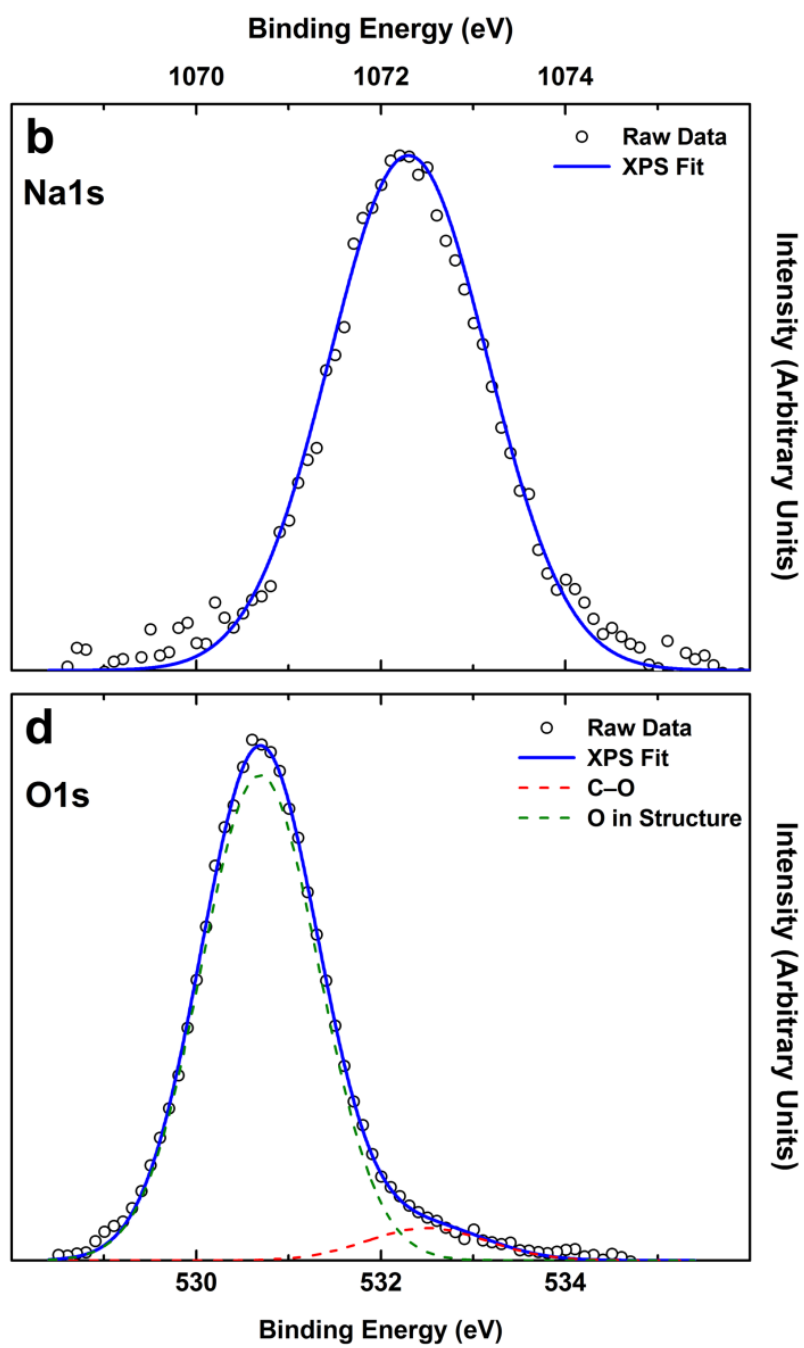

Fig. 2 XPS spectra for (a) K2p, (b) Na1s, (c) Nb3d, and (d) O1s core levels for as-deposited KNN thin film grown under $20 \%$ oxygen partial pressure.
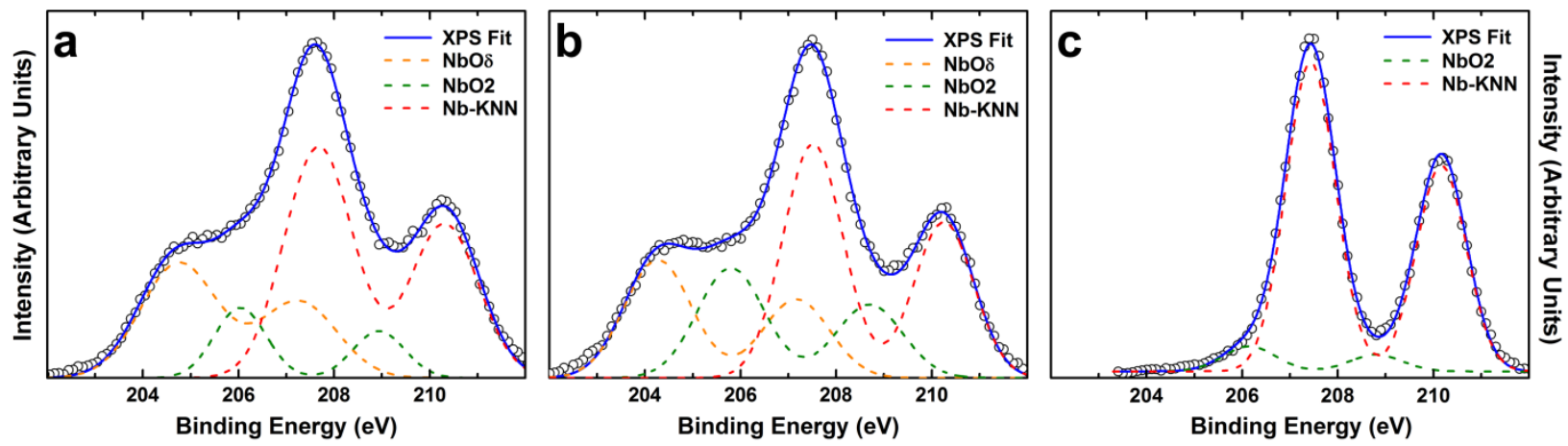

Fig. $3 \mathrm{Nb3d}$ spectra of the films grown under $20 \%$ oxygen partial pressure: (a) as-deposited, (b) post-annealed for $1 \mathrm{~h}$ in vacuum, and (c) post-annealed 20 for $1 \mathrm{~h}$ in oxygen. 

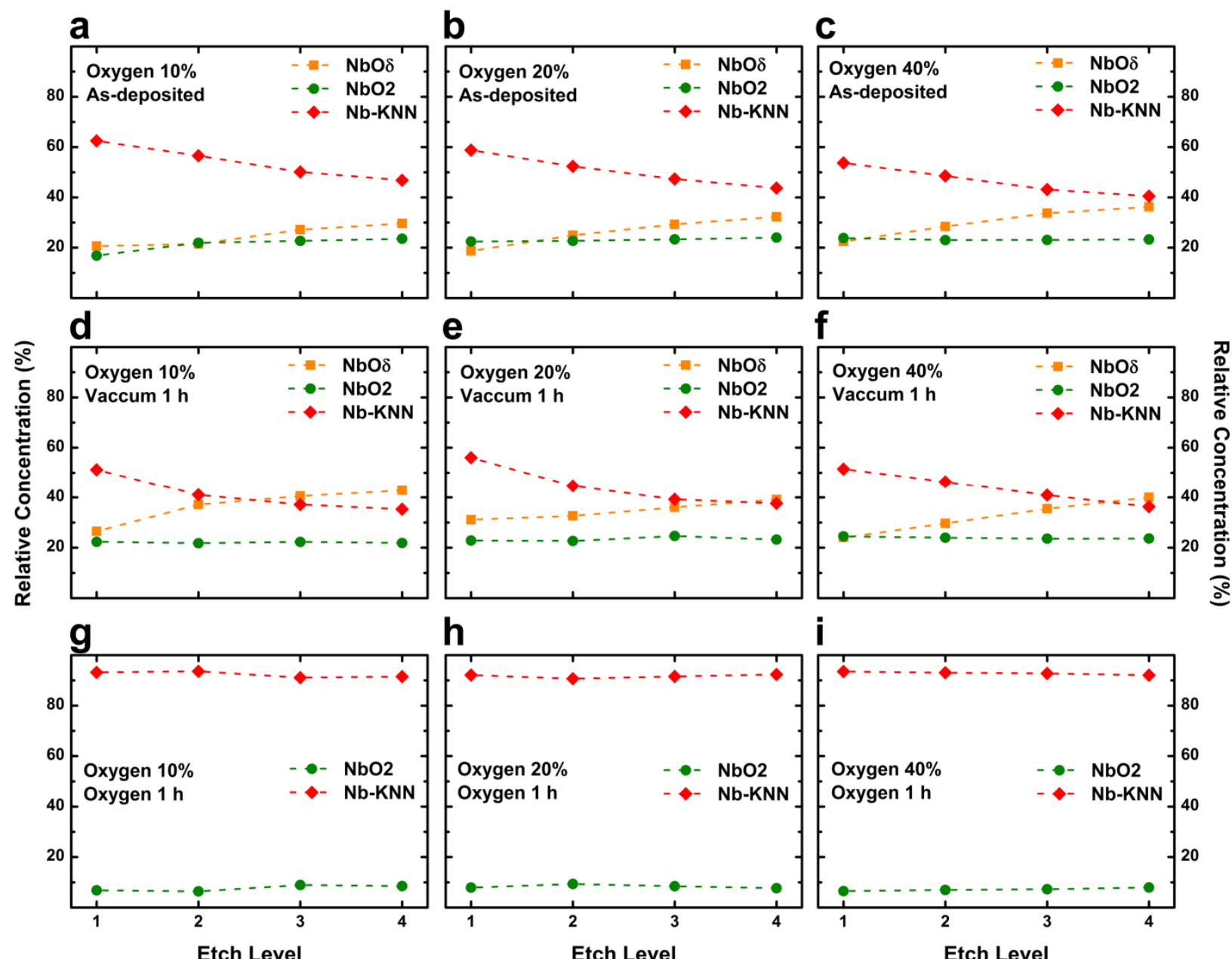

Fig. 4 Relative percentage concentrations of the $\mathrm{NbO}_{\delta}, \mathrm{NbO}_{2}$, and Nb-KNN species at consecutive etching levels of the KNN thin films studied (a,b,c) asdeposited and subjected to post-annealing treatment in $(\mathrm{d}, \mathrm{e}, \mathrm{f})$ vacuum for $1 \mathrm{~h}$ and $(\mathrm{g}, \mathrm{h}, \mathrm{i})$ oxygen for $1 \mathrm{~h}$ and grown with $(\mathrm{a}, \mathrm{d}, \mathrm{g}) 10 \%,(\mathrm{~b}, \mathrm{e}, \mathrm{h}) 20 \%$, and (c,f,i) $40 \%$ oxygen partial pressure.

5 To study the effects of post-annealing treatments on the crystal structure of thin films, powder diffraction XRD was conducted on the post-annealed samples. Figure 5 presents and compares X-ray diffractograms of as-deposited and post-annealed samples for the films grown under oxygen partial pressures of $10 \%$ and $20 \%$.

10 For thin films grown under $10 \%$ oxygen partial pressure at $700{ }^{\circ} \mathrm{C}$, post-deposition annealing in an oxygen atmosphere for $1 \mathrm{~h}$ at $700{ }^{\circ} \mathrm{C}$ results in considerable growth of $\mathrm{KNN}(002)$ and $\mathrm{KNN}$ (101) orientations, and the suppression of $\mathrm{NbO}_{2}$ as observed in the XRD results [Fig. 5(a)]. ${ }^{43,44}$ The KNN (111) peak

15 intensity also decreases, indicating the re-orientation of KNN crystal structure in (002) and (101) directions. Films grown under $20 \%$ oxygen partial pressure however, exhibit the growth of KNN crystal structure in (111) direction following post-deposition annealing in oxygen atmosphere [Fig. 5(b)]. Secondary niobium 20 oxide peaks are reduced in intensity in these samples as well indicating the formation and growth of higher order $\mathrm{Nb}^{5+}$ oxidization states, as a result of the annealing treatment, complementary to the results of the XPS analysis (Figs. 3 and 4). These XRD results, considering in combination with the XPS 25 outcomes, allude to the possibility of engineering the crystalline orientation and alkali ratio in KNN thin films through varying the oxygen partial pressure during the sputtering process coupled with specific post-annealing treatments.

Previous studies on the RF magnetron sputtering of KNN thin 30 films have shown that the composition and the growth rate of KNN thin films are not influenced by growth temperature. ${ }^{17,18,24}$ Further, the crystalline orientation of KNN thin films was proven to be dependent on the growth temperature. To substantiate this hypothesis and to test the primary premise that the RF plasma can 35 determine alkali ratios (and thereby, film composition), we carried out depositions on a modified substrate and at a lower temperature. 

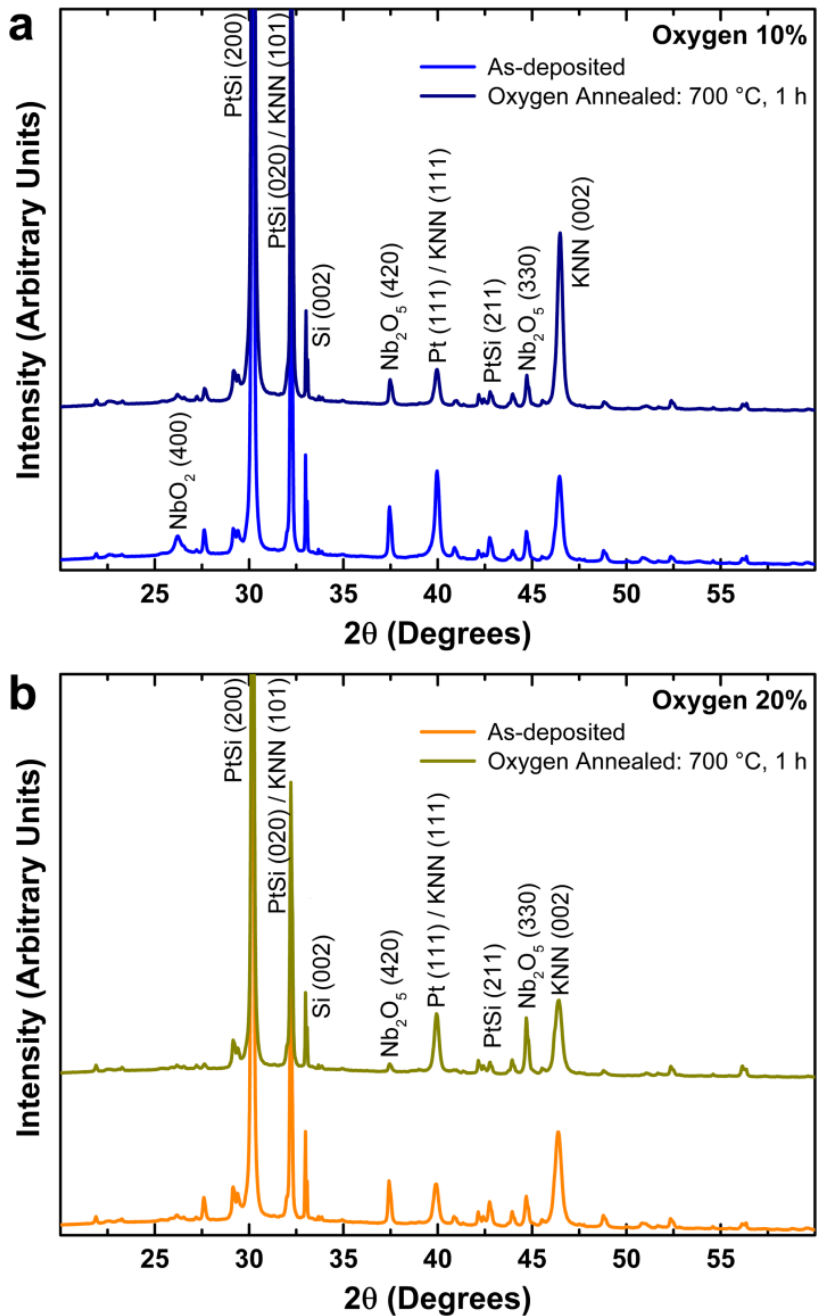

Fig. 5 X-ray diffractograms for $\mathrm{KNN}$ thin films as-deposited at $700^{\circ} \mathrm{C}$ and further annealed in oxygen at $700{ }^{\circ} \mathrm{C}$ for $1 \mathrm{~h}$. Thin film deposition was carried out at oxygen partial pressures of (a) $10 \%$ and (b) $20 \%$.

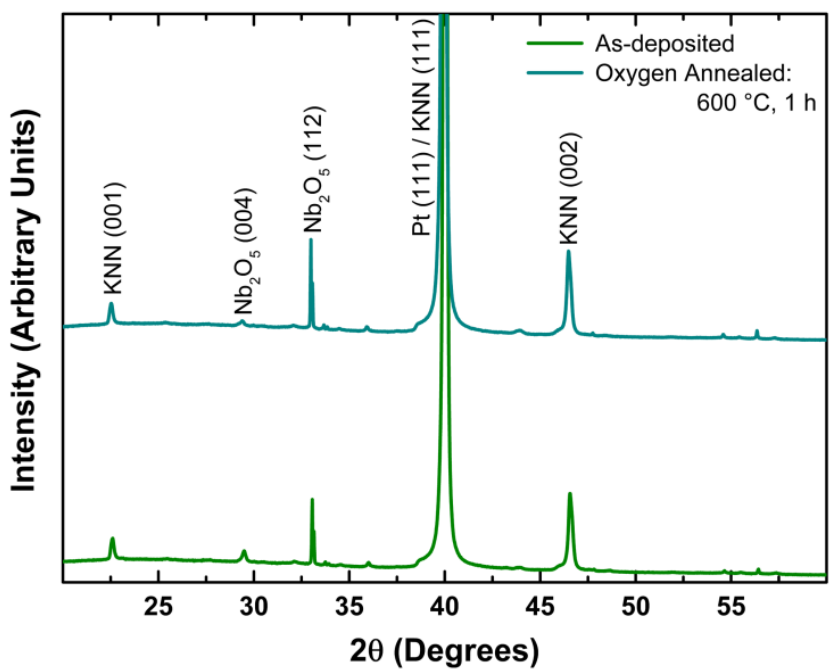

Fig. 6 X-ray diffractograms for $\mathrm{KNN}$ thin films as-deposited at $600{ }^{\circ} \mathrm{C}$ and annealed in oxygen at $600{ }^{\circ} \mathrm{C}$ for $1 \mathrm{~h}$.
$\mathrm{KNN}$ thin films were deposited on $\mathrm{Pt} / \mathrm{Ti} / \mathrm{SiO}_{2} / \mathrm{Si}$ substrates at the growth temperature of $600{ }^{\circ} \mathrm{C}$ and post-annealed at $600{ }^{\circ} \mathrm{C}$ in oxygen atmosphere for $1 \mathrm{~h}$. Figure 6 shows the X-ray diffractograms for as-deposited and post-annealed thin films grown under $20 \%$ oxygen partial pressure at $600{ }^{\circ} \mathrm{C}$.

$15 \mathrm{The}^{\mathrm{SiO}} 2$ barrier layer utilized on silicon substrates prior to deposition of platinum thin film prevents the formation of the PtSi layer during deposition at high substrate temperature. ${ }^{45}$ As a result, the as-deposited nano-crystalline platinum crystallizes into the thermodynamically stable (111) configuration on exposure to 20 higher temperatures. The resulting KNN thin films show strong $c$ axis (001) orientation with the absence of the KNN (101) peak. Single crystalline nature of platinum layer as opposed to the polycrystalline $\mathrm{Pt}-\mathrm{Si}$ layer also prevents the formation of crystalline phases for secondary niobium oxide species. The 25 composition of $\mathrm{KNN}$ thin films deposited at $600{ }^{\circ} \mathrm{C}$ was examined after post-annealing treatment in oxygen via XPS, revealing its $\mathrm{K} /(\mathrm{K}+\mathrm{Na})$ ratio to be $44.2 \%$, almost identical to the film grown under $20 \%$ oxygen partial pressure at $700{ }^{\circ} \mathrm{C}$ and post-annealed in oxygen for $1 \mathrm{~h}$. The $(\mathrm{K}+\mathrm{Na}) / \mathrm{Nb}$ ratio was $3043.9 \%$, slightly lower than the ratio at $700{ }^{\circ} \mathrm{C}$. These XPS results highlight that the changes in the deposition temperature and the substrate do not significantly influence the RF plasma diffusivity determined alkali loss and alkali-niobium ratio.

\section{Conclusions}

35 The ability to control alkali concentration and ratio in lead-free KNN thin films has been examined. It has been shown that the lighter alkali species (sodium) experiences greater scattering in the deposition atmosphere; while both alkali species are significantly scattered in comparison to niobium. These results 40 highlight the need to account for such loss in species during the RF sputtering process by tailoring the initial sputtering target composition. Such alkali ratio control by varying oxygen partial pressure, independent of substrate temperature and configuration, also provides a mechanism to vary dopant concentrations in thin 45 film samples using just one sputtering target of fixed composition. Further, the stabilization of the KNN phase has been achieved through the elimination of secondary phases using a facile high-temperature post annealing process in oxygen atmosphere. Moreover, the effect of substrate orientation and ${ }_{50}$ crystallinity on the crystal structure of high temperature RFsputtered KNN thin films was highlighted. Results for thin films sputtered at $600{ }^{\circ} \mathrm{C}$ on platinized silicon substrates with thermally grown $\mathrm{SiO}_{2}$ barriers signal the formation of a strongly (111) textured platinum layer which in turn leads to a strong orientation

${ }_{55}$ in the KNN thin films. This further highlights the significance of temperature control during the RF deposition which allows for the effective control of the orientation in metallic substrate layer and in turn the preferential orientation in KNN perovskite oxide thin films.

\section{${ }_{60}$ Acknowledgements}

Funding support for the project from the Australian Research Council (ARC) through Discovery Projects DP1092717 and DP130100062 and infrastructure grants LE0882246 and LE0989615 are acknowledged. V.B., S.S., and M.B. 
acknowledge Australian Post-Doctoral Fellowships from the ARC through DP0988099, DP110100262, and DP1092717, respectively. The authors also acknowledge the facilities and technical assistance of the Australian Microscopy \& 5 Microanalysis Research Facility at the RMIT Microscopy \& Microanalysis Facility.

\section{Notes and references}

${ }^{a}$ Functional Materials and Microsystems Research Group, School of Electrical and Computer Engineering, RMIT University, Melbourne, 10 Victoria 3001, Australia.E-mail: sharath.sriram@gmail.com, madhu.bhaskaran@gmail.com

${ }^{b}$ NanoBiotechnology Research Lab, School of Applied Sciences, RMIT

University, Melbourne, Victoria 3001, Australia.

${ }^{c}$ School of Applied Sciences, RMIT University, Melbourne, Victoria 3001, 15 Australia.

1. Y. P. Guo, K. Kakimoto and H. Ohsato, Mater. Lett., 2005, 59, 241244.

2. E. Hollenstein, M. Davis, D. Damjanovic and N. Setter, Appl. Phys. 20 Lett., 2005, 87.

3. T. Saito, T. Wada, H. Adachi and I. Kanno, Japanese Journal of Applied Physics, 2004, 43, 6627.

4. G. Shirane, R. Newnham and R. Pepinsky, Physical Review, 1954, 96, 581-588.

25 5. M. Blomqvist, S. Khartsev, A. Grishin, A. Petraru and C. Buchal, Appl. Phys. Lett., 2003, 82, 439-441.

6. S. I. Khartsev, M. A. Grishin and A. M. Grishin, Appl. Phys. Lett., 2005,86 .

7. H. J. Lee, C. W. Ahn, S. H. Kang, I. W. Kim, J. S. Lee and B. M. Jin, Ferroelectrics, 2006, 335, 227-232.

8. I. Kanno, T. Ichida, K. Adachi, H. Kotera, K. Shibata and T. Mishima, Sensors and Actuators A: Physical, 2012.

9. K. Shibata, F. Oka, A. Ohishi, T. Mishima and I. Kanno, Applied Physics Express, 2008, 1, 1501.

35 10. Y. Wakasa, I. Kanno, R. Yokokawa, H. Kotera, K. Shibata and T. Mishima, Sens. Actuator A-Phys., 2011, 171, 223-227.

11. K. Tanaka, K. Kakimoto and H. Ohsato, J. Cryst. Growth, 2006, 294, 209-213.

12. F. P. Lai and J. F. Li, Ferroelectrics, 2007, 358, 1063-1069.

40 13. L. Y. Wang, K. Yao and W. Ren, Appl. Phys. Lett., 2008, 93.

14. C. W. Ahn, S. Y. Lee, H. J. Lee, A. Ullah, J. S. Bae, E. D. Jeong, J. S. Choi, B. H. Park and I. W. Kim, J. Phys. D-Appl. Phys., 2009, 42.

15. M. Abazari, T. Choi, S. W. Cheong and A. Safari, J. Phys. D-Appl. Phys., 2010, 43.

45 16. M. Abazari and A. Safari, J. Appl. Phys., 2009, 105.

17. X. Wang, S. Olafsson, L. D. Madsen, S. Rudner, I. P. Ivanov, A. Grishin and U. Helmersson, J. Mater. Res., 2002, 17, 1183-1191.

18. V. M. Kugler, F. Soderlind, D. Music, U. Helmersson, J. Andreasson and T. Lindback, J. Cryst. Growth, 2003, 254, 400-404.

50 19. I. Kanno, T. Mino, S. Kuwajima, T. Suzuki, H. Kotera and K. Wasa, IEEE Trans. Ultrason. Ferroelectr. Freq. Control, 2007, 54, 25622566.

20. K. Shibata, F. Oka, A. Nomoto, T. Mishima and I. Kanno, Japanese Journal of Applied Physics, 2008, 47, 8909.

55 21. K. Shibata, K. Suenaga, K. Watanabe, F. Horikiri, A. Nomoto and T. Mishima, Japanese Journal of Applied Physics, 2011, 50.
22. B. Y. Kim, T. G. Seong, I. T. Seo, M. S. Jang, S. Nahm, J. Y. Kang and S. J. Yoon, Acta Mater., 2012, 60, 3107-3112.

23. X. Wang, U. Helmersson, S. Olafsson, S. Rudner, L. D. Wernlund 60 and S. Gevorgian, Appl. Phys. Lett., 1998, 73, 927-929.

24. V. M. Kugler, F. Soderlind, D. Music, U. Helmersson, J. Andreasson and T. Lindback, J. Cryst. Growth, 2004, 262, 322-326.

25. C. Zaldo, D. S. Gill, R. W. Eason, J. Mendiola and P. J. Chandler, Appl. Phys. Lett., 1994, 65, 502-504.

65 26. H. Pfisterer and K. Schubert, Z. Metallk., 1950, 41, 358-367.

27. M. Ahtee and A. W. Hewat, Acta Crystallogr. Sect. A, 1975, 31, 846850 .

28. M. Ahtee and A. W. Hewat, Acta Crystallogr. Sect. A, 1978, 34, 309317.

70 29. M. Zeman, C. Fulton, G. Lucovsky, R. Nemanich and W.-C. Yang, J. Appl. Phys., 2006, 99, 023519-023519-023516.

30. F. Pesty, H.-P. Steinrück and T. E. Madey, Surface science, 1995, 339, 83-95.

31. M. Bhaskaran, S. Sriram, S. Ruffell and A. Mitchell, Advanced Functional Materials, 2011, 21, 2251-2257.

32. Powder Diffraction Pattern Files, International Centre for Diffraction Data (ICDD), Newtown Square, PA 19073, Card 47-2025.

33. L. Castaldi, M. R. J. Gibbs and H. A. Davies, J. Appl. Phys., 2003, 93, 9165-9169.

80 34. S. M. Rossnegal, I. Yang and J. J. Cuomo, Thin Solid Films, 1991, 199, 59-69.

35. S. Sriram, M. Bhaskaran, J. d. Plessis, K. T. Short, V. P. Sivan and A. S. Holland, Micron, 2009, 40, 104-108.

36. J. A. Thornton, Annual review of materials science, 1977, 7, 239-260.

85 37. J. A. Thornton, Journal of Vacuum Science and Technology, 1974, 11, 666-670.

38. D. A. Shirley, Phys. Rev. B, 1972, 5.

39. V. Bansal, A. Syed, S. K. Bhargava, A. Ahmad and M. Sastry, Langmuir, 2007, 23.

90 40. K. Jung, Y. Kim, Y. S. Park, W. Jung, J. Choi, B. Park, H. Kim, W. Kim, J. Hong and H. Im, J. Appl. Phys., 2011, 109, 054511-054514.

41. N. Magnussen, L. Quinones, D. C. Dufner, D. L. Cocke, E. A. Schweikert, B. K. Patnaik, C. V. B. Leite and G. B. Baptista, Chemistry of Materials, 1989, 1, 220-225.

95 42. S. Kundu, Y. Wang, W. Xia and M. Muhler, The Journal of Physical Chemistry C, 2008, 112, 16869-16878.

43. M. Ahtee and A. W. Hewat, Acta Crystallogr. Sect. A, 1975, 31, 846850 .

44. M. Ahtee and A. W. Hewat, Acta Crystallogr. Sect. A, 1978, 34, 309$100 \quad 317$.

45. S. Sriram, M. Bhaskaran, A. Mitchell, D. Mitchell and G. Kostovski, Nanoscale Res. Lett., 2008, 4, 29-33. 